\title{
Job burnout: The contribution of emotional stability and emotional self-efficacy beliefs
}

\author{
Guido Alessandri ${ }^{\text {* }}$ (D), Enrico Perinelli' (D), Evelina De Longis', \\ Wilmar B. Schaufeli ${ }^{2,3}$, Annalisa Theodorou ${ }^{4}$, Laura Borgogni ', \\ Gian Vittorio Caprara' and Luigi Cinque' \\ 'Department of Psychology, Sapienza University of Rome, Italy \\ ${ }^{2}$ Department of Social, Health \& Organisational Psychology, Utrecht University, The \\ Netherlands \\ ${ }^{3}$ Department of Work, Organisational and Personnel Psychology, KU Leuven, Belgium \\ ${ }^{4}$ Department of Social and Developmental Psychology, Sapienza University of Rome, Italy
}

\begin{abstract}
Consistent with insights from both trait and social cognitive theories, this study presents a theoretical model positing emotional self-efficacy beliefs in managing negative emotions at work as a key mechanism that contributes to mediate the negative relationship between emotional stability - a trait highly associated with positive affect and mental health - and job burnout. To test this assertion, a two-wave study using a representative sample of 416 new military cadets of an Italian military academy was designed. Military cadets were involved in the study 2 months after their entrance into the academy and then again, a year later. Results from structural equation modelling supported the hypothesized model. As predicted, self-efficacy beliefs in managing negative emotions at work significantly mediated the longitudinal relation between emotional stability and job burnout, even after controlling for the effect of the other Big Five traits, education, previous experience in military contexts, gender, and age. Practical implications and directions for future research are discussed. In conclusion, our study demonstrates that self-efficacy in managing negative emotions at work represents an important mechanism linking emotional stability level to burnout symptoms.
\end{abstract}

\section{Practitioner points}

- Self-efficacy in managing negative emotions at work proved to be an important resource for workers in managing job-related stress: practitioners interested in reducing burnout symptoms in stressful working environments should take into account this variable.

- Self-efficacy beliefs in managing negative emotions at work are cognitive structures malleable to change. Literature on social cognitive theory offers several suggestions on how to promote individuals' positive beliefs on managing negative emotions and dysphoric affect. Hence, findings and literature reported in this study may be useful for practitioners aiming at strengthen workers' self-efficacy in managing negative emotions at work, through the development and application of coaching and training programmes.

*Correspondence should be addressed to Guido Alessandri, Department of Psychology, Sapienza University of Rome, Via dei Marsi 78, Rome 00185, Italy (email: guido.alessandri@uniroma I.it). 
Burnout is a work-related syndrome that results from prolonged exposure to emotional and interpersonal stressors (Demerouti, Bakker, Nachreiner, \& Schaufeli, 2001; Maslach, Schaufeli, \& Leiter, 2001). The experience of burnout has been consistently associated to negative individual and organizational outcomes such as anxiety, depression, and life dissatisfaction (Ahola, 2007; Hakanen \& Schaufeli, 2012), mood disturbances (Hillhouse, Adler, \& Walters, 2000), impaired job performance (Bakker \& Heuven, 2006; Wright \& Bonett, 1997), turnover (Schaufeli \& Enzmann, 1998), and absenteeism (Schaufeli, Bakker, \& Van Rhenen, 2009). Most of the existing research on burnout, however, has focused on situational factors as antecedents of burnout, whereas few studies have addressed the possibility that personality characteristics have a decisive impact on the burnout process (Bakker, Demerouti, \& Sanz-Vergel, 2014).

Yet, recent studies and meta-analyses have underlined the role of personality factors as potential antecedents of burnout pointing to emotional stability as the most influential personality trait (Alarcon, Eschleman, \& Bowling, 2009; Swider \& Zimmerman, 2010). Nonetheless, the potential mechanisms linking broad traits to burnout remain largely unexamined. The present contribution expands this line of research, by proposing a theoretical model linking a particular basic personality trait, namely emotional stability, to job burnout through the mediation of self-efficacy beliefs in managing negative emotions at work.

Studies of job burnout-personality relationships have tended to be conducted using cross-sectional data (see Alarcon et al., 2009, p. 258; Swider \& Zimmerman, 2010, p. 495) and with reference to static theoretical frameworks. This state of the art is unsatisfactory. Indeed, building a comprehensive theoretical model sensitive to the nature of the direct and indirect relationships between personality and job burnout requires moving beyond static models of their associations. First, if certain personality traits (e.g., low emotional stability) determine a basic individual's susceptibility to developing job burnout, these symptoms take time to appear. Consequently, models of personality-job burnout relationships that ignore time may be incapable of describing the nuances, or perhaps even the broader relationship between these two constructs. Second, hypothesizing the presence of mediating mechanisms linking personality to job burnout symptoms implies introducing the notion of time as a key factor for understanding the relationship. Indeed, any mediational hypothesis naturally implies a temporally ordered sequence of influences, that, in this case, go from personality to increased emotional self-efficacy beliefs and ends with a reduction in job burnout symptoms. Most importantly, the above hypothesis is impossible to test with cross-sectional (or static) data models (Maxwell \& Cole, 2007). Finally, a mediational hypothesis is only one of a set of alternative hypothesis that can reasonably be put forward to explain the occurrence of a phenomenon. If certain personality traits promote an individual's vulnerability to job burnout, it is equally likely that a reversed effect of job burnout on personality is a theoretical alternative that should be investigated and excluded to strengthen the appropriateness of the theoretical model. As Cole and Maxwell (2003) have pointed out, although cross-sectional investigations are informative, an exhaustive testing of alternative theoretical hypotheses can only be carried out with temporally spaced data.

In this study, utilizing two waves of longitudinal data, we extended previous investigations by implementing a longitudinal research design that allowed for a better test of mediation. In doing so, it contributes to the literature in several ways. Indeed, to our knowledge, no researchers have longitudinally examined the direct and indirect relations among personality, self-efficacy beliefs in managing negative emotions at work, and job 
burnout. We argue that such a study is necessary to better assess the likely direction of causal influences among these job-related variables.

First, by considering self-efficacy beliefs in managing negative emotions at work as the mediator of emotional stability, classical trait theories (McCrae \& Costa, 2008) and social cognitive theory (Bandura, 1997, 2001) are naturally combined. This allows researchers a larger theoretical breath by integrating two rival theories in the research on burnout antecedents (Alarcon et al., 2009; Consiglio, Borgogni, Alessandri, \& Schaufeli, 2013). Second, the use of longitudinal data to disentangle the causal direction among variables allows the testing of alternative models that assume different causal directions among the study variables (Cole \& Maxwell, 2003; Maxwell \& Cole, 2007). Finally, we conducted our study on a complete cohort of military cadets first enrolled in one of the most prestigious military schools in Italy, thus combining the advantages of a naturally representative sample and maximizing the ecological validity of the results. We believe that their position as newcomers adds strength to the empirical test of our model. Indeed, newcomers are likely to experience stress because they have to adjust to a novel and demanding environment, acquire a new role, learn new skills, and in general, have to adapt to a new social and organizational life (Ellis et al., 2015). Moreover, both emotional stability and self-efficacy beliefs in managing negative emotions have been shown to be key determinants of newcomers' adjustment, because they affect the level of perceived work stress during the first year (see Ellis et al., 2015; Joardar \& Matthews, 2010; Jones, Smith, \& Johnston, 2005; Saks, 1994; Spector \& O’Connell, 1994).

\section{Personality and job burnout}

The value of personality traits for predicting work-related outcomes has been widely demonstrated (Bakker, Van Der Zee, Lewig, \& Dollard, 2006; Judge, Jackson, Shaw, Scott, \& Rich, 2007; Maslach et al., 2001). In general, trait theories conceptualize workers' personality as a hierarchical organization of temporally stable patterns of affect, cognition and behaviours, linkable to endogenous basic tendencies that contribute to set the potential of individuals' behaviour (McCrae \& Costa, 2008). Over the years, a large consensus has been gained about five basic personality factors (extraversion, agreeableness, conscientiousness, emotional stability, and openness to experience) considered as the basis of humans' personality. These personality traits, also known as the Big Five, are deemed to account for most of the individual differences in personality (John, Naumann, \& Soto, 2008). Furthermore, the Big Five model has a long-standing research tradition within organizational psychology. In particular, empirical studies, meta-analyses, and systematic reviews have shown strong associations between Big Five traits and workrelated outcomes, such as job performance (Barrick \& Mount, 1991; Hurtz \& Donovan, 2000), job satisfaction (Judge, Heller, \& Mount, 2002), counterproductive work behaviour (Salgado, 2002), and career success (Seibert \& Kraimer, 2001). As such, the Big Five model seems to be a suitable and well-established framework to study the effect of individual differences on work-related variables.

The observation that certain workers are more inclined than others to develop work stress, and consequently burnout (see Maslach et al., 2001), has naturally lead researchers to investigate the association between the Big Five and job burnout. Empirical studies have repeatedly pointed to emotional stability (or to its pole opposite, namely emotional instability or neuroticism) as the prime individual characteristic that is associated, in a negative direction, with burnout symptoms (Schaufeli \& Enzmann, 1998). Simply stated, emotional stability refers to an individual's capability to adequately cope with negative 
emotions, such as stress, anxiety, discontent, irritability, and anger (Barbaranelli \& Caprara, 2000; Costa \& McCrae, 1992).

Theoretically, low emotional stability seems to operate as a kind of individual vulnerability to stress, or a diatesis, namely a basic predisposition to develop job burnoutrelated symptoms. On the contrary, high emotional stability represents personal resources that operates as a protective factor, making individuals more resilient and thus less prone to develop job burnout (Hobfoll, 1989, 2001). This theoretical interpretation of the role of high emotional stability as a personal protective resource is supported by a host of empirical studies. Workers who report low scores on this factor tend to be anxious, insecure, depressed, fearful, and nervous (McCrae \& Costa, 2008). Moreover, low emotional stability is related to the use of ineffective coping strategies such as denial, wishful thinking, and self-criticism (Bolger, 1990; Heppner, Cook, Wright, \& Johnson, 1995).

Thus, the large body of literature supporting a significant association between emotional instability and burnout is not surprising (e.g., Alarcon et al., 2009; Swider \& Zimmerman, 2010). Among the Big Five personality traits, emotional instability demonstrates the highest and most consistent associations with each of the burnout components across studies (see Alarcon et al., 2009; Bakker et al., 2006; Kim, Shin, \& Swanger, 2009; Kim, Shin, \& Umbreit, 2007), and it is currently considered the best trait predictor of burnout (Kim et al., 2009; Maslach et al., 2001). Whereas this result is mostly based on cross-sectional studies (see Alarcon et al., 2009, p. 259; Hakanen \& Bakker, 2017, p. 354; or Swider \& Zimmerman, 2010), it is also supported in a handful (i.e., $N=4$ ) of longitudinal studies currently available (Armon, Shirom, \& Melamed, 2012; Deary, Watson, \& Hogston, 2003; Goddard, Patton, \& Creed, 2004; Piedmont, 1993).

In a large meta-analytic study, Alarcon et al. (2009) examined the unique and combined effects of personality traits on three burnout dimensions (emotional exhaustion, depersonalization, and personal accomplishment). The authors found that emotional stability showed the strongest associations with emotional exhaustion and depersonalization after controlling for the other personality factors $(\beta=-.45$ in affecting emotional exhaustion and $\beta=-.29$ in affecting depersonalization; Alarcon et al., 2009, p. 256). A subsequent meta-analysis conducted by Swider and Zimmerman (2010) further confirmed Alarcon et al.'s findings; in fact, their results demonstrated that 'of all of the personality traits examined, neuroticism [the negative pole of emotional stability] has the strongest relationship with emotional exhaustion and depersonalization' (Swider \& Zimmerman, 2010, p. 494).

\section{Self-efficacy beliefs in managing negative emotions at work and burnout}

According to social cognitive theorists, personality can be defined as both a cognitive and affective system that derives from the combined action of different structures that gradually take form during the course of development (Bandura, 2001). The focus of social cognitive theory is on the psychological mechanisms of human functioning that make people active agents in their life course (Bandura, 1999). According to this perspective, individuals are proactive and creative and capable of creating courses of action leading to desired outcomes (Bandura, 1991, 1999). Consistently, the emphasis of social cognitive theory is on the core features of personal agency such as intentionality, forethought, selfregulation, and self-reflectiveness (Bandura, 2001).

In particular, social cognitive scholars contend that self-efficacy beliefs, namely the beliefs people hold about their ability to exert control on their life beyond the 
impact of external causes (e.g., negative life events), exert a pervasive influence on personality functioning (Bandura, 1997). For instance, several findings have documented the important role of self-efficacy beliefs in affecting emotion, cognition, motivation, choice, and action, across domains of functioning such as learning (e.g., on academic performance), work (e.g., on work adjustment and career development), social adjustment (e.g., on interpersonal relationships), and health (e.g., on health-related behaviours; for a review, see Bandura, 1997). Thus, focusing on selfefficacy beliefs as expressions of contextual knowledge has been critical for clarifying their properties across tasks and situations. Given the multifaceted and context-specific nature of self-efficacy beliefs, social cognitive theory has broadened its programme of research and extended the study of perceived self-efficacy to those mechanisms of human agency able to regulate the inter-relationship between one's stable factors (i.e., personality traits) and psychosocial functioning in different contexts.

Among the mechanisms of human agency, self-efficacy beliefs operate as a key factor in the adaptation and motivation process, influencing individual's action, both directly and indirectly. Self-efficacy beliefs represent the judgements people hold about their capability to succeed in specific situations (Bandura, 1997). The assumption is that the perception of control over one's own functioning and environment influences the type of actions individuals choose to undertake and their perseverance despite difficulties. Hence, self-efficacy beliefs play a significant part in the process of developing competencies (Bandura, 2001).

It is important to note that the relationship between burnout and self-efficacy has been addressed in several previous studies, using measures of general self-efficacy (Alarcon et al., 2009; Shoji et al., 2016). However, according to social cognitive theory, self-efficacy beliefs are knowledge structures about specific domains of functioning. Embracing such a theoretical perspective, this study focuses on perceived self-efficacy associated with the regulation of negative emotions at work (Alessandri, Vecchione, \& Caprara, 2015). More specifically, workers' self-efficacy beliefs in managing negative emotions at work consists of individuals' beliefs in their capability to recover from negative emotional states raised by negative events or adversities and to avoid being overwhelmed by negative emotions such as anxiety, anger, and irritation (see Caprara, 2002; Caprara et al., 2008). Workers who do not believe that they can control emotions associated with recurrent daily hassles or serious struggles are unlikely to adapt to novel and unfamiliar situations, to respond flexibly to stressful circumstances, and to encounter life with curiosity and enthusiasm (Consiglio et al., 2013).

Previous studies have shown that individuals with higher self-efficacy beliefs in managing negative emotions report less negative affect, anxiety, and depression (see Alessandri et al., 2015, for a review) and that negative emotional self-efficacy beliefs predict changes in stable personality traits, such as emotional stability (Caprara, Vecchione, Barbaranelli, \& Alessandri, 2013) and positive orientation (Caprara, Alessandri, \& Barbaranelli, 2010). In general, studies addressing the relationship between emotional intelligence, a construct closely related although distinct from emotional selfefficacy beliefs (see Alessandri et al., 2015), and work-related stress support a negative association of individuals' ability to identify, process, and effectively manage emotions in order to attain goals, better adapt, and cope with challenges (see Petrides, 2011), stress (Chan, 2006; Mikolajczak, Menil, \& Luminet, 2007; Ullrich, Lambert, \& McCarthy, 2012), and burnout (Zysberg, Orenshtein, Gimmon, \& Robinson, 2017). 


\section{Traits and emotional self-efficacy beliefs}

Traits and self-efficacy beliefs in managing negative emotions at work refer to distinct constructs that belong to different theoretical perspectives. Traits may be defined as 'dimensions of individual differences in tendencies to show consistent patterns of thought, feelings and actions' (McCrae \& Costa, 1990, p. 23). On the other hand, selfefficacy beliefs in managing negative emotions at work reflect processes and mechanisms that enable people to reflect on their functioning and gain advantages from their work experiences (Caprara et al., 2013). Furthermore, in contrast to personality traits, selfefficacy beliefs in managing negative emotions at work represent highly contextualized functioning structures that at first, affect appraisal processes, and then guide actions (Bandura, 1997).

Thus, in our theoretical model, personality traits and self-efficacy beliefs in managing negative emotions at work are considered constructs that refer to different levels in the structure of personality. Personality traits are stable and broad dispositions that contribute causally to the development of behaviours, attitudes, and abilities, as well as other characteristic adaptations (McCrae \& Costa, 2008). In contrast, self-efficacy beliefs in managing negative emotions at work are functioning structures (i.e., a set of self-related beliefs), which operate in between broad dispositions and specific behaviours, and refer to an individuals' perceived competence in regulating emotions and behaviours (McAdams, 1995).

Our model rests on the idea that differences in worker's personality should be studied considering different levels (i.e., traits and self-processes) of personality (Caprara et al., 2013; McAdams, 1995). Furthermore, it adheres to the distinction made by McAdams (1995) in terms of levels of analysis, identifying self-efficacy beliefs in managing negative emotions at work as a mediator, which allows a workers' basic disposition, namely emotional stability, to translate into specific behaviours. This is supported by previous studies that have shown that self-efficacy beliefs in managing negative emotions may act as mediators of the influence exerted by personality on behaviour (Caprara, Alessandri, Di Giunta, Panerai, \& Eisenberg, 2010; Caprara, Alessandri, \& Eisenberg, 2012) and that reciprocal effects may exist so that self-efficacy beliefs in managing negative emotions at work may influence the development of personality traits (Caprara et al., 2013).

\section{Aim of the study}

This study aimed to investigate the role of self-efficacy beliefs in managing negative emotions at work as the mediator of the relationship between personality traits and burnout symptoms, using a two-wave design in which the stability of constructs was kept under control while considering all possible alternative pathways. We aimed to expand the current literature by (1) providing a solid mediational test based on a robust two-wave design, (2) accounting for the temporal ordering among variables, (3) using latent variables (and thus controlling for measurement error), (4) including all Big Five traits at once, and (5) controlling for a set of relevant covariates. A schematic representation of our theoretical model is displayed in Figure 1.

In this study, burnout is conceptualized as a syndrome composed by the three dimensions of emotional exhaustion, cynicism, and interpersonal strain at work (ISW). The latter dimension was recently proposed to recapture the original interpersonal component of burnout (i.e., depersonalization) that was lost in the process of transforming the original burnout questionnaire that could only be applied in human 


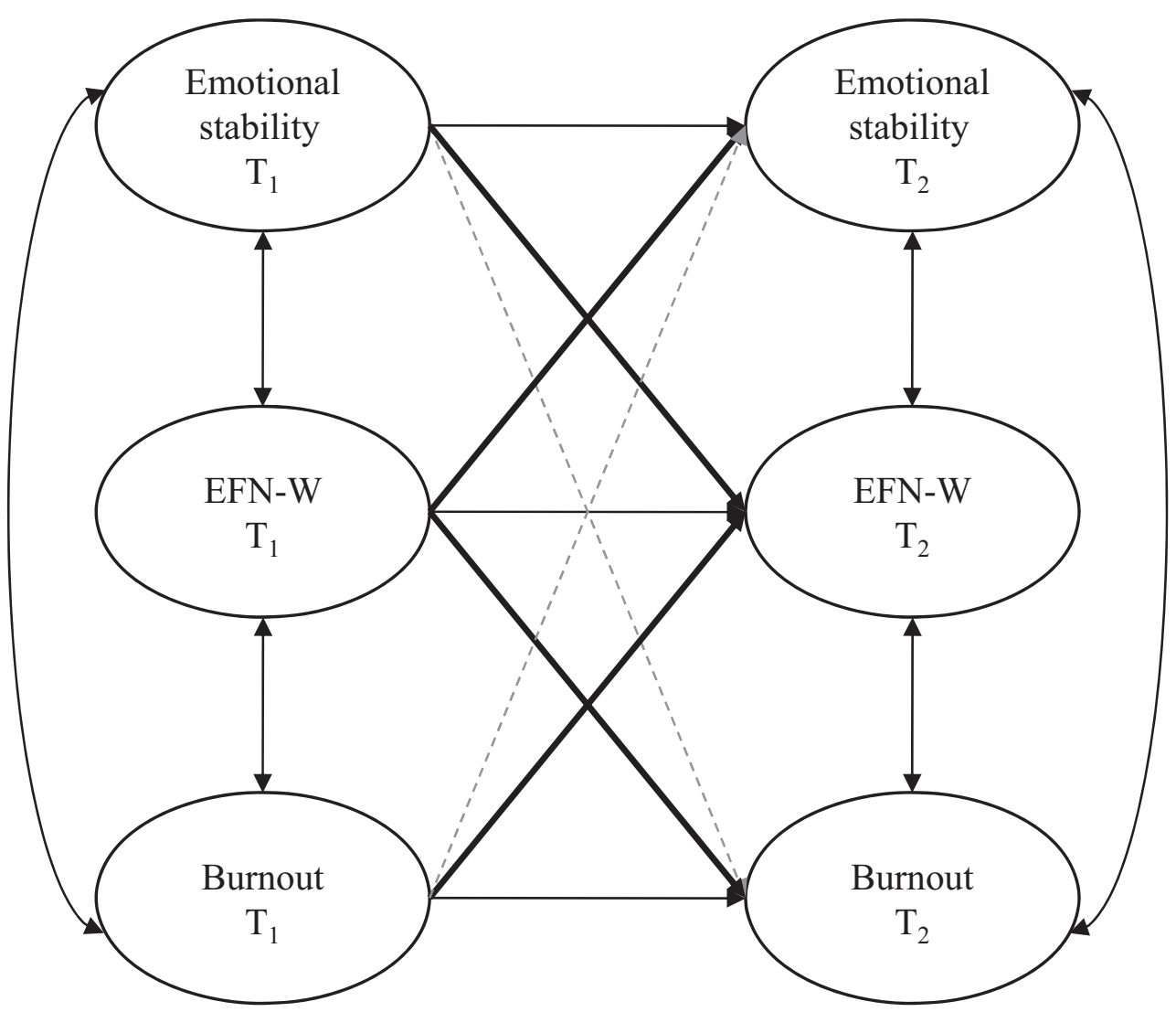

Figure I. The hypothesized mediation model. Note. Solid black lines represent hypothesized direct paths, and dashed grey lines represent hypothesized indirect paths. In this model, self-efficacy beliefs in managing negative emotions at work mediate the relationship between emotional stability and burnout (Hypotheses I-3) as well as the relationship between burnout and emotional stability (Hypotheses 4-6). EFN-W = Self-efficacy beliefs in managing negative emotions at work.

service settings into a questionnaire that can be used in any organizational setting. ISW is defined as a feeling of discomfort and disengagement with people at work resulting from excessive pressure and demands (Borgogni, Consiglio, Alessandri, \& Schaufeli, 2012). It may occur in all work contexts, and it is particularly relevant in those settings where there is a strong interpersonal component, such as in the military. This interpersonal strain component becomes particularly salient in our sample of new cadets, who are called upon to adapt to a new and challenging social environment.

Our first hypothesis is that worker's emotional stability constitutes the basis for individuals' ability to effectively handle negative emotional states at work. According to contemporary perspectives (Caspi, Roberts, \& Shiner, 2005; Roberts, Wood, \& Caspi, 2008), traits represent workers' basic predispositions towards certain patterns of thought, feeling, and behaviour. Self-efficacy beliefs, on the other hand, represent mediating mechanisms that mostly account for their actualization (Caprara et al., 2013). More generally, according to Caprara et al. (2013), workers' perceived capabilities for successful self-regulation are set by their natural predisposition to experience negative 
emotions or emotional stability. Accordingly, the more workers are predisposed to experience anxious and dysphoric and depressive states, the lower is their expected ability to effectively handle these emotions. In turn, individuals who are less able to manage their negative emotions in cases of stressful or threatening situations may inappropriately express their emotional states (Eisenberg et al., 2001) or may be overwhelmed by them. Following recommendations by Judge et al. (2007), we included all traits to control for their shared variance. However, we expected a significant prediction of self-efficacy beliefs in managing negative emotions at work (and thus an indirect effect on burnout) only in the case of emotional stability, as it is the only attested personality trait in previous empirical studies (see Caprara et al., 2013).

Hypothesis 1: Emotional stability significantly predicts self-efficacy beliefs in managing negative emotions at work over time.

Hypothesis 2: Self-efficacy beliefs in managing negative emotions at work significantly predict burnout over time.

The better the worker's ability to deal with negative emotions, the higher their resistance to stress, and thus, the lower the risk of developing burnout symptoms. Social cognitive theory (Bandura, 1997) suggests that self-efficacy beliefs in managing negative emotions at work are likely to guide the selection of individuals' responses across various situations. Workers with robust self-efficacy beliefs avoid overestimating external threats, of overreacting, or of being hyper-sensitive to frustration. Previous studies have attested a significant relationship between self-efficacy beliefs in managing negative emotions and the ability to flexibly react to negative experiences across time and situations (see Milioni et al., 2015). Other studies indicate that perceived self-regulatory efficacy plays a key role in determining the different consequences of negative affect and supports a negative association between self-efficacy in managing negative affect and depression (Bandura, Caprara, Barbaranelli, Gerbino, \& Pastorelli, 2003). All in all, these results suggest that selfefficacy in managing negative emotions may contribute to individuals' adjustment and functioning. Combining hypotheses 1 and 2 brings us to our third hypothesis, namely:

Hypothesis 3: Self-efficacy beliefs in managing negative emotions at work significantly mediate the relationship between emotional stability and burnout over time.

The idea here is that self-efficacy beliefs in managing negative emotions at work represent cognitive structures that reflect a psychological process leading to the actualization of potentials into actual individual work-related outcomes. The consistently positive and significant correlation between emotional stability and burnout may result from the lack of statistical control over mediating processes (i.e., self-efficacy beliefs in managing negative emotions at work). In sum, our model is in harmony with recent studies (Caprara et al., 2013) that consider emotional stability as the dispositional basis of self-efficacy beliefs in managing negative emotions.

\section{Alternative but theoretically plausible longitudinal pathways}

In addition to the directional predictions suggested in Hypotheses 1, 2, and 3, there are also theoretical arguments that speak to alternative directions of effects that should be incorporated in our model, and empirically tested. Indeed, according to the conservation of resources theory (COR; Hobfoll, 1989), job burnout occurs when individuals 
experience a net loss of physical, cognitive, or emotional resources, generated by a prolonged exposure to work stress (Hobfoll \& Shirom, 2001). COR theory also postulates that when individuals are confronted with a loss, they tend to adopt a defensive posture in order to protect their remaining resources (Hobfoll, 2001). This defensive response allows individuals to minimize their losses and to keep remaining resources readily available in case of a future loss. This process can lead to a successful adaptation and generation of new resources, or, in contrast, to an unsuccessful adaptation, which is related to negative functional and emotional outcomes (Hobfoll, 2001). As a consequence, the condition of resources impairment - namely burnout - may have an impact on selfefficacy beliefs in managing negative emotions at work by reducing workers' emotional responsiveness and reactivity to the organizational environment. Specifically, individuals who report high levels of emotional exhaustion may have depleted their resources, which are necessary to regulate their emotions, and thus report a lower perceived ability for emotional regulation.

Hypothesis 4: Job burnout predicts self-efficacy beliefs in managing negative emotions at work over time.

Finally, we do not exclude that, in the long run, self-efficacy beliefs in managing negative emotions at work may contribute to shape and thus change workers' basic emotional stability. Indeed, as stated by Caprara et al. (2013), self-efficacy beliefs mostly account for what is due to experience and malleable; as a consequence, the more 'people became capable to handle their negative emotions, and to express their positive emotions, the more they became able to preserve a sort of composure in the face of challenges and adversities and the less vulnerable they are to mood fluctuations' ( $\mathrm{p}$. 147). Moreover, social cognitive theory explicitly suggests that increasing individuals' self-regulatory abilities positively impacts their ability to express positive and negative affect, to deal with dysphoric emotional states, and to strengthen their resistance to stress (Bandura, 1997). Hence, on the basis of the above theoretical arguments, we formulated the following:

Hypothesis 5: Self-efficacy beliefs in managing negative emotions at work predict emotional stability over time.

The combination of hypotheses 4 and 5 leads us to a final possible indirect pathway within our model, namely the indirect effect of job burnout on emotional stability via selfefficacy in managing negative emotions at work.

Hypothesis 6: Self-efficacy beliefs in managing negative emotions at work significantly mediate the relationship between job burnout and emotional stability over time.

In performing the analyses below, we controlled for the effect of gender and age, given that they are significantly associated with emotional stability (Costa, Terracciano, \& McCrae, 2001; Specht, Egloff, \& Schmukle, 2011), emotional self-efficacy (Alessandri et al., 2015), and burnout (Brewer \& Shapard, 2004; Purvanova \& Muros, 2010). To take into account the effect of different levels of organizational socialization among cadets coming from other sections of the military organization, we also controlled for first experience in a military organization. Finally, level of education was included as a covariate because it has been associated with susceptibility to burnout in previous studies (see Maslach et al., 2001). 


\section{Method}

\section{Participants and research context}

Military cadets included in this study represent a complete cohort of 416 individuals who applied for and were selected for enrolment in the first year of one of the most prestigious military academies in Italy, belonging to the Guardia di Finanza, an Italian law enforcement agency of the Minister of Economy and Finance aimed at supporting the adjustment of new cadets into the military. As such, the present data are naturally representative of military cadets entering the academy. Ages ranged from 19 to 32 $(M=22.86, S D=2.29) ; 284$ were males $(68.3 \%)$ and 132 were females $(31.7 \%)$. Although participants were fresh military cadets, about a quarter of them had previous experience in another military organization $(114 ; 27.4 \%)$. They were assigned to this military academy upon their specific request. For these latter individuals, being admitted (after a competitive procedure) to this academy resulted in an improvement of their work role and salary. The majority of the sample had a high school degree $(355,85.3 \%)$, and 61 subjects (14.7\%) had a university degree. Data at T1 were collected in May 2015, 2 months after the academic year had started. In March of 2016, T2 data were collected. The choice of the time-lag was determined by the annual cycle of cadets' evaluation in the academy and thus for practical and not theoretical reasons.

\section{Procedure}

Military cadets provided their responses after logging into computers at the academy under direct supervision of a specifically trained psychologist. The psychologist did not interfere in any way with participants, but only introduced them to the procedure and showed them how to interact with the electronic version of the test battery. Military cadets were randomly assigned by human resource managers to one of four groups of individuals (each composed of about 104 members) who completed the battery at different times during the same day.

\section{Attrition analysis and missing data consideration}

Loss of participants is common in longitudinal designs. In this study, 53 participants (12.7\%) dropped out at T2 (34 males and 19 females), thus leaving 363 cadets (retention rate: $87.3 \%$ ). A series of one-way ANOVAs showed that participants included only at T1 and those who remained at T2 did not significantly differ on any of the study variables. Moreover, the Missing Completely At Random (MCAR) Little's test (Enders, 2010) confirmed that the data satisfied the assumption of being MCAR $\left(\chi^{2}=32.594, d f=26\right.$, $p=.174)$, as implied by the Full Information Maximum Likelihood (FIML) estimation procedure used to estimate all subsequent models (Enders, 2010). Hence, no systematic dropout occurred.

\section{Measures}

\section{Personality traits}

Personality traits were measured using the Big Five Questionnaire-2 (BFQ-2; Caprara, Barbaranelli, Borgogni, \& Vecchione, 2007). The BFQ-2 assesses five domains (extraversion, agreeableness, conscientiousness, openness, and emotional stability) with eight 
items for each domain, thus comprising 40 items in total. Respondents indicated agreement with the extent to which each item described them on a 5-point scale ranging from complete disagreement $(1=$ very false for $m e)$ to complete agreement $(5=$ very true for me). The alpha reliability coefficients at T1 and T2 were .86 and .83 for agreeableness, .76 and .75 for conscientiousness, .77 and .77 for extraversion, .90 and .86 for emotional stability, and .80 and .81 for openness.

\section{Self-efficacy in managing negative emotions at work}

Participants rated their perceived self-efficacy in managing negative emotions at work with six items (see Appendix) of the Regulatory Emotional Self-Efficacy (RESE) scale (Caprara et al., 2008), adapted for organizational contexts (Alessandri \& Caprara, 2017). Respondents indicated agreement with the extent to which each item described them on a 5-point scale ranging from 1 (not well at all) to 5 (very well). Items ask respondents to rate how well he/she manages his/her negative events at work, such as keep calm during stressful situations and job-related frustrations, and avoiding anger for wrongs suffered. The alpha reliability coefficients at T1 and T2 were .86 and .83 , respectively.

\section{Burnout}

Burnout was measured as a latent variable consisting of emotional exhaustion, cynicism, and interpersonal strain. Emotional exhaustion was measured by five items from the Maslach Burnout Inventory - General Survey (MBI-GS; Maslach, Jackson, \& Leiter, 1996; Italian version: Borgogni, Galati, Petitta, \& Centro Formazione Schweitzer, 2005) assessing the frequency at which a respondent experiences negative feelings such as work-related exhaustion, stress, and tiredness. The response scale ranged from 0 (never) to 6 (everyday). Cynicism was measured by five items from the MBI-GS assessing the frequency at which a respondent experiences feelings of emotional detachment, loss of meaning and skepticism about his/her job. Interpersonal strain was measured by seven items of the Interpersonal Strain at Work scale (ISW; Borgogni et al., 2012), assessing the frequency at which a respondent experiences 'disengagement reaction from all relevant interpersonal relationships at work' (Borgogni et al., 2012, p. 876). The alpha reliability coefficients at T1 and T2 were .85 and .87 for emotional exhaustion, .74 and .80 for cynicism, and .93 and .91 for interpersonal strain.

\section{Covariates}

Covariates (as described in the 'Participants and research context' paragraph) were all measured at $\mathrm{T} 1$ and coded as follows: Education $(0=$ no university degree, $1=$ yes university degree $)$, first experience in a military organization $(0=n o, 1=y e s)$, gender $(0=$ male, 1 = female $)$, and age.

\section{Data analytic strategy}

In testing our theoretical model, we used an autoregressive, cross-lagged design, currently recognized as being one of the strongest and less biased designs to assess mediation using two time points (Maxwell \& Cole, 2007). In particular, two-wave mediation models may be more effective than pure cross-sectional designs in that they: (1) allow a better investigation (although not a test) of the likely causal direction among variables, (2) avoid 
bias in testing for mediation, and (3) allow for more stringent testing of alternative models (Cole \& Maxwell, 2003; Maxwell \& Cole, 2007). In our model, the mediator (i.e., selfefficacy beliefs in managing negative emotions at work) was predicted over time by emotional stability (see MacKinnon, 2008). Under this framework, the product of the coefficients associated with (1) the link of T1 emotional stability with T2 self-efficacy beliefs in managing negative emotions at work and to (2) the relation of T1 self-efficacy beliefs in managing negative emotions at work with T2 burnout provide an estimate of the partial regression coefficient associated with the mediated effect from emotional stability to burnout. Furthermore, the inclusion of autoregressive paths allows taking into account the stability of the construct and thus more reliable estimates of the parameters representing the cross-lagged relationships among the study variables are obtained. Corroborating the hypothesized mediation model under these rather stringent conditions would support its validity.

Practically, we implemented our hypothesized model (see Figure 1) in several steps. First, we built a measurement model including all seven variables (i.e., the Big Five traits, self-efficacy beliefs in managing negative emotions at work and burnout) at both T1 and T2, as latent factors with loadings of these specific indicators. Given the large number of items of each construct, and to avoid estimating unnecessarily complex models, we identified each variable as a latent factor by individuating a relatively small subset of parcels loading on each of them. In particular, parcels are aggregates of individual items that serve as observed indicators for measuring latent variables (Little, Cunningham, Shahar, \& Widaman, 2002). In situations like the present one, where interest is on the prospective relations among constructs, the use of parcels offers several advantages, such as higher reliability and better model estimations (Little, Rhemtulla, Gibson, \& Schoemann, 2013). We built parcels following the suggestions provided by Little et al. (2002, p. 166). Accordingly, we arranged four parcels for each Big Five trait, resulting in two items per parcel, and three parcels for the measure of self-efficacy beliefs in managing negative emotions at work, resulting in two items per parcel. The same items for each parcel were used at T1 and T2. Burnout was measured using the composite scale scores of emotional exhaustion, cynicism, and interpersonal strain.

We first estimated a model (i.e., Model 1) in which (1) all seven latent variables (i.e., the Big Five traits, self-efficacy beliefs in managing negative emotions at work and burnout) were allowed to covary at $\mathrm{T} 1$, (2) all seven latent variables at T2 were regressed on the corresponding seven latent variables at T1, (3) all residuals of parcels at T1 were allowed to correlate with their counterparts at T2, and (4) all residuals of latent variables at T2 were allowed to correlate. Then, we moved to Model 2, where estimated factor loadings were set to be equal across time (weak invariance), and then to Model 3, where each latent variable was regressed onto four covariates (i.e., gender, age, education, and first experience in a military organization). Finally, Model 4 represents the revised version of the Model 3, with all non-significant effects of covariates fixed to zero.

\section{Statistical analyses}

We used structural equation modelling (SEM) to evaluate the statistical model using the Mplus software program, version 7.4 (Muthén \& Muthén, 1998-2015). To deal with missing data, we used FIML (see Arbuckle, 1996). To evaluate fit of the hypothesized model to the data (see Kline, 2016 for an overview), we used the standard chi-square index 
of statistical fit that is routinely provided under maximum likelihood estimation of parameters, as well as the root mean square error of approximation (RMSEA) and the Comparative Fit Index (CFI). The RMSEA is an absolute index of fit with values under .05 indicating a close fit to the data. For the CFI, fit index values should be $>.90$ to consider the fit of a model to be acceptable.

Finally, mediated effects were calculated using the procedures outlined by MacKinnon, Lockwood, Hoffman, West, and Sheets (2002). The values for the upper and lower confidence intervals (CI) for indirect effects were tested using the Monte Carlo method for assessing mediation CI method (Hayes \& Scharkow, 2013) with 20,000 replications.

To compare the fit of the nested models, we used the likelihood ratio tests $\left(\Delta \chi^{2}\right)$ with a conservative level of Type 1 error $(\alpha)$ set to .01 (see Cheung \& Rensvold, 2002); furthermore, we also took into account differences in CFI ( $\triangle$ CFI) and in Akaike's information criterion $(\triangle \mathrm{AIC})$ : Acceptable values for considering the more parsimonious model as non-significantly worse than the comparison model are $\Delta \mathrm{CFI}<.01$ (Cheung \& Rensvold, 2002) and $\triangle \mathrm{AIC}<4$ (Burnham \& Anderson, 2004).

\section{Results}

\section{Zero-order correlations}

\section{Concurrent correlations}

Cross-sectionally, variables were highly correlated (Table 1). At T1, among the Big Five traits only emotional stability showed two non-significant correlations (i.e., with openness and extraversion). Of interest for our study, we found that burnout at T1 was significantly and negatively correlated with agreeableness, self-efficacy in managing negative emotions at work and emotional stability, whereas it showed negligible zeroorder correlations with conscientiousness, extraversion, and openness. In contrast, at T2, all zero-order correlations were significant at $p<.05$ and ranged from $|.12|$ (self-efficacy in managing negative emotions at work with openness) to $|.76|$ (emotional stability with burnout). Worthy of note, at both T1 and T2, burnout showed the highest correlations with emotional stability $(r=-.79, z=-32.514, p<.001$ at $\mathrm{T} 1 ; r=-.76, z=-25.686$, $p<.001$ at T2).

\section{Longitudinal correlations}

All longitudinal zero-order correlations (Table 1) were significant at $p<.05$, except openness T1 with emotional stability T2, emotional stability T1 with openness $\mathrm{T} 2$, and self-efficacy in managing negative emotions at work T1 with openness T2. Again, burnout showed the highest correlations with emotional stability; indeed, $r=-.48(z=-9.486$, $p<.001)$ for burnout T1 with emotional stability T2 and $r=-.49(z=-10.496$, $p<.001$ ) for emotional stability T1 with burnout T2.

\section{Structural equation models}

As displayed in Table 2, all models showed a reasonable fit to the data, according to the above-mentioned criteria. Most importantly, constrained models did not fit worse than more liberal models and thus, we move to interpreting results under Model 4, which represents the most restrictive version of our hypothesized model. 


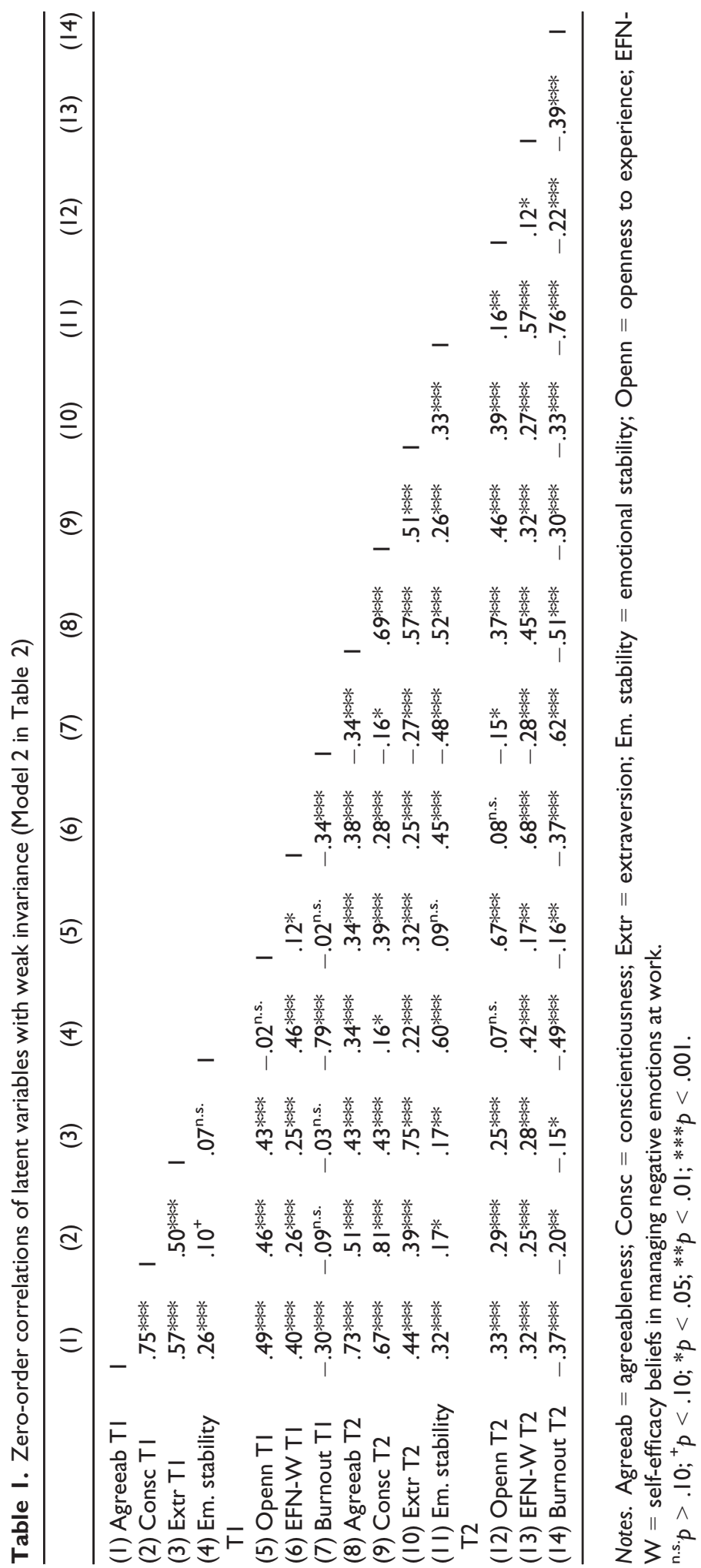




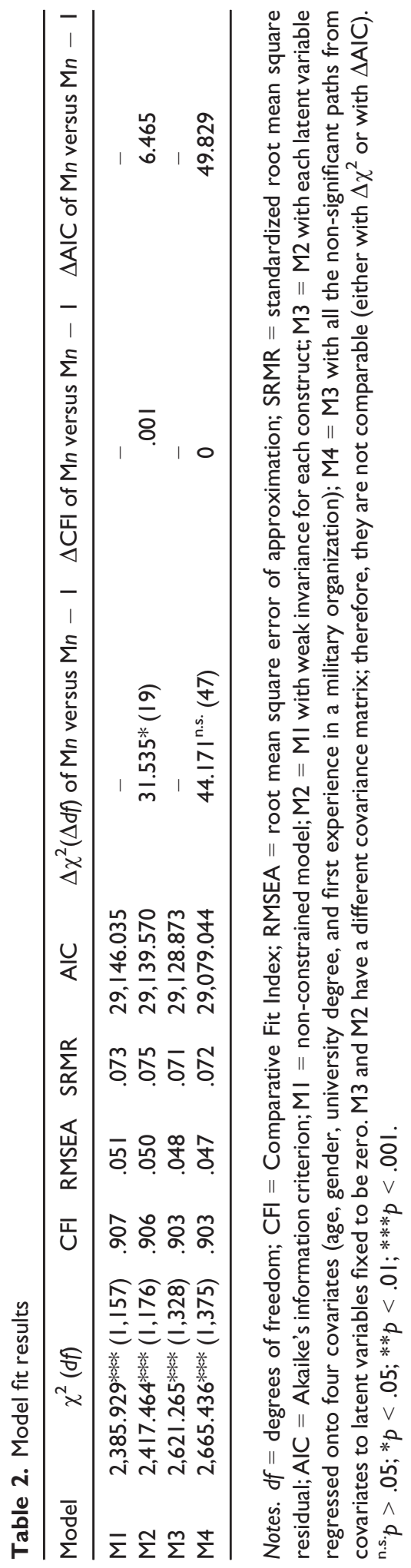




\section{Measurement models}

In the measurement models, all constructs were specified as correlated latent variables each loaded by three or four parcels. Standardized factor loadings for agreeableness ranged from .74 to $.87(M=0.79, S D=0.06)$ at $\mathrm{T} 1$ and from .66 to $.84(M=0.76, S D=0.08)$ at T2 Standardized factor loadings for conscientiousness ranged from .57 to $.75(M=0.65$, $S D=0.08)$ at $\mathrm{T} 1$ and from .59 to $.74(M=0.65, S D=0.07)$ at $\mathrm{T} 2$. Standardized factor loadings for extraversion ranged from .65 to $.81(M=0.72, S D=0.07)$ at $\mathrm{T} 1$ and from .61 to $.84(M=0.71, S D=0.10)$ at $\mathrm{T} 2$. Standardized factor loadings for emotional stability ranged from .64 to $.92(M=0.84, S D=0.13)$ at $\mathrm{T} 1$ and from .58 to $.89(M=0.80, S D=0.15)$ at $\mathrm{T} 2$. Standardized factor loadings for openness ranged from .65 to $.91(M=0.76, S D=0.13)$ at T1 and from .64 to $.90(M=0.77, S D=0.14)$ at T2. Self-efficacy in managing negative emotions at work was composed by three parcels: Standardized factor loadings were .82 , .83 , and .85 at $\mathrm{T} 1$ and $.79, .80$, and .83 at $\mathrm{T} 2$. The latent variable measuring burnout was composed by three composite scores: Standardized factor loadings at T1 were .76 for emotional exhaustion, .86 for cynicism, and .90 for interpersonal strain; standardized factor loadings at $\mathrm{T} 2$ were .77 for emotional exhaustion, .88 for cynicism, and .88 for interpersonal strain. All of the factor loadings presented above had $p$ values lower than .001 .

\section{Autoregressive paths}

As can be seen from Tables 1 and A1 (see Appendix for the latter), all variables were highly stable across the two time points. Retest correlations (Table 1) ranged from $r=.60$ $(z=14.521, p<.001)$ for emotional stability to $r=.81(z=23.771, p<.001)$ for conscientiousness $(M=0.69, S D=0.07)$ and autoregressive paths (Table A1 in Appendix) ranged from $\beta=.47(z=5.265, p<.001)$ for emotional stability to $\beta=.78$ $(z=14.407, p<.001)$ for extraversion $(M=0.64, S D=0.10)$.

\section{Hypothesized cross-lagged paths and mediation analyses}

In accordance with our hypotheses (see Figure 2), $\left(\mathrm{H}_{1}\right)$ higher individual scores on emotional stability at T1 predicted higher self-efficacy in managing negative emotions at work at $\mathrm{T} 2(\beta=.23, z=2.536, p=.011)$, and $\left(\mathrm{H}_{2}\right)$ higher individual scores on self-efficacy in managing negative emotions at work at $\mathrm{T} 1$ significantly predicted lower levels of burnout at T2 $(\beta=-.13, z=-2.042, p=.041)$. The significance of these paths supported the hypothesis that emotional self-efficacy beliefs in managing negative emotions at work fully mediate the longitudinal relation between emotional stability and burnout, given that the direct path from emotional stability at $\mathrm{T} 1$ to burnout at $\mathrm{T} 2$ was not statistically significant. To further corroborate this conclusion, we tested whether the longitudinal relationship between emotional stability at T1 and burnout at T2 was mediated through emotional selfefficacy beliefs in managing negative emotions at work. The resulting unstandardized indirect effect was -0.064 , and the associated CI did not include zero (lower confidence limit $=-0.001$; upper confidence limit $=-0.163$ ), therefore supporting mediation.

On the contrary, the hypothesis of the reversed mediation effect $\left(\mathrm{H}_{6}\right)$ was not supported, given that $\left(\mathrm{H}_{5}\right)$ higher self-efficacy in managing negative emotions at work at T1 predicted higher individual scores in emotional stability at T2 $(\beta=.18, z=2.941$, $p=.003)$, but $\left(\mathrm{H}_{4}\right)$ burnout at $\mathrm{T} 1 \mathrm{did}$ not significantly predict self-efficacy in managing negative emotions at work at $\mathrm{T} 2$.

Among the non-hypothesized cross-lagged paths (see Table A1 in Appendix), we found evidence for a longitudinal effect of burnout at T1 on extraversion at T2 $(\beta=-.31$, 
$z=-3.412, p=.001)$. Accordingly, a higher starting level of burnout decreases extraversion over time.

Overall, the model explains a substantial amount of variance in burnout (43.6\%; see Table A1 in Appendix for the explained variance of the other constructs).

\section{Control variables}

The control variables were analysed in relation to all latent variables and kept in the model if they were significant. Compared to males, females showed higher levels of openness at both T1 $(\beta=.18, z=3.847, p<.001)$ and T2 $(\beta=.11, z=2.531, p=.011)$, agreeableness at T1 $(\beta=.15, z=3.412, p=.001)$ and conscientiousness at T1 $(\beta=.12, z=2.368$, $p=.018$ ). In contrast, males (coded as 0 ) scored higher only on self-efficacy in managing negative emotions at work at $\mathrm{T} 1(\beta=-.19, z=-4.166, p<.001)$ and emotional stability at T1 $(\beta=-.16, z=-4.473, p<.001)$. The condition of 'first experience in a military organization' seemed to affect only emotional stability at T1 $(\beta=.09, z=2.576$, $p=.010)$ : Given the positive sign of this relationship, those who lived a previous military

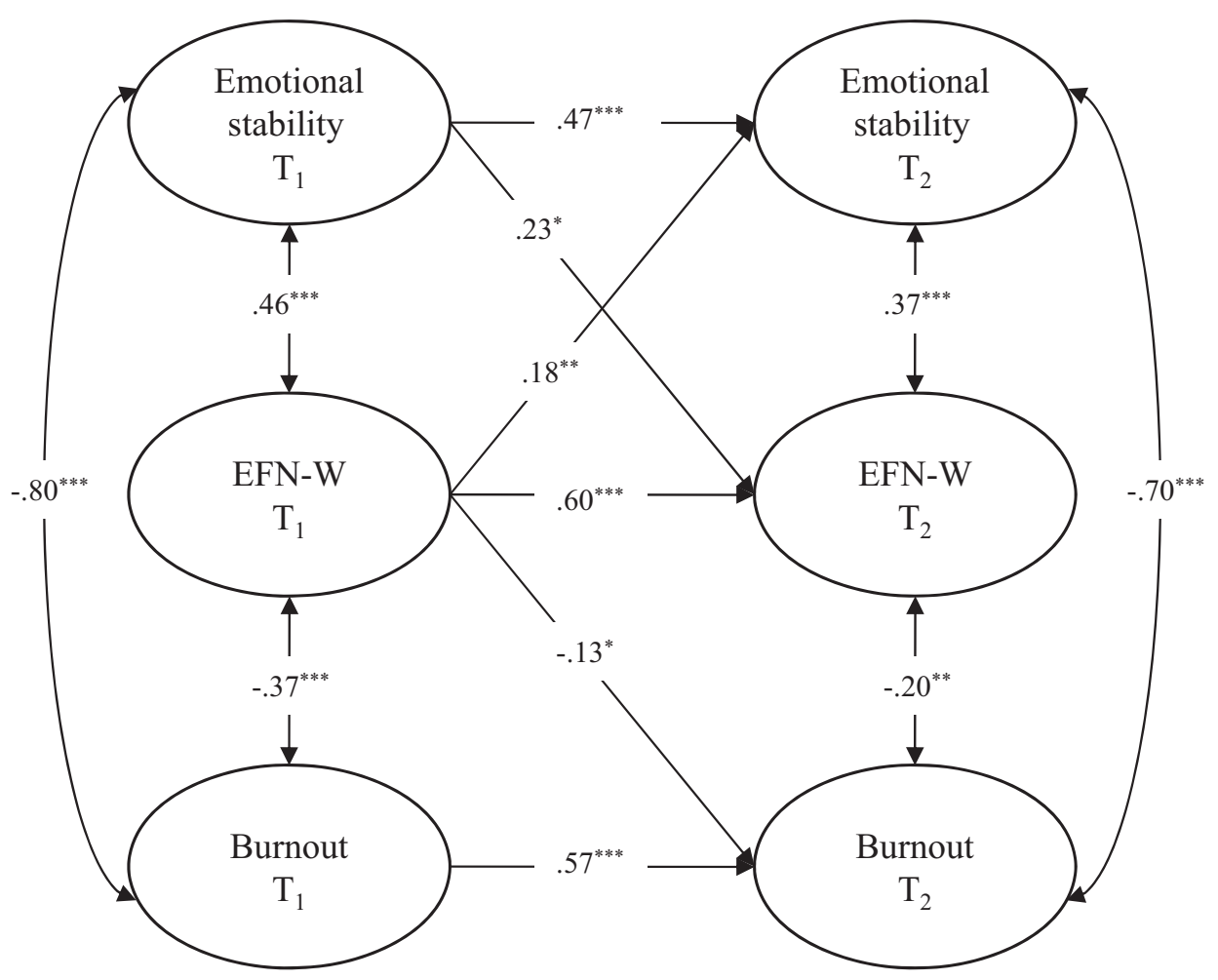

Figure 2. The hypothesized model with standardized estimates. Note. This figure represents a simplified version of Model 4 (see Table 2). For the sake of clarity, non-significant paths, covariates, and four of the Big Five were omitted from the figure. The effects of covariates were reported in text (see the paragraph 'Control variables' in the Results section). Full details about the parameter estimates (i.e., regression paths and covariances) linking the Big Five, self-efficacy beliefs in managing negative emotions at work, and burnout are presented in Tables AI and A2 in Appendix. EFN-W = Self-efficacy beliefs in managing negative emotions at work. 
experience seemed to have lower levels of emotional stability. Age positively affected openness at $\mathrm{T} 1(\beta=.12, z=2.812, p=.005)$ and self-efficacy in managing negative emotions at work at T1 $(\beta=.09, z=2.120, p=.034)$. Finally, education (University degree) did not affect any variable.

\section{Discussion}

Using a theoretical model that is based on both trait and social cognitive theory (Caprara, 2002; Caprara et al., 2013), the current study investigates the dynamic interplay of a basic personality trait, namely emotional stability, with self-efficacy regarding the management of emotions, and burnout, focusing on emotional stability as one of the most important personality factors in protecting workers from burning out. We used a representative sample of cadets, which was followed for almost 1 year starting from their initial entry into a prestigious military academy in Italy, and were then asked to adapt to a new and challenging work environment. Our data offer a suitable perspective regarding the relationship between emotional stability and self-efficacy beliefs in managing negative emotions at work and job burnout, and support a theoretical model (Caprara, 2002; Caprara et al., 2013) that offers several insights into how to prevent burnout in an organizational context. We discuss our results and their implications in detail below.

The Big Five model of personality and the social cognitive construct of work selfefficacy beliefs have occupied prominent roles in organizational psychology during the last decades, offering two different frameworks for looking at predictors of occupational health outcomes. Specifically, the trait theory of personality based on the Big Five model (McCrae \& Costa, 2008) conceived individual behaviour as an expression of interindividual differences in the hierarchical organization of stable patterns of cognition, affect, and behaviour. Social cognitive theory, in contrast, conceptualizes organizational behaviour as resulting from the synergistic action of different cognitive structures. Previous studies have separately applied each approach to the study of job burnout. Our study concurs recent perspectives on the explanation of organizational behaviour (i.e., Jackson, Hill, \& Roberts, 2012), demonstrating that both positions may complement each other.

Indeed, results from the empirical test of our theoretical model strongly support the idea that emotional stability represents the most important personality trait protecting workers against the development of burnout symptoms. The relationship between workers' emotional stability and burnout, however, is not direct. Instead, workers' emotional stability seems to set the basis for their perceived ability to manage negative emotions. Workers high in emotional stability show a naturally increased ability to deal with negative work-related emotions, and this latter seems to ensure them a higher resistance to stress. It appears that emotional self-efficacy beliefs in managing negative emotions at work is the key mechanism that protects workers from developing burnoutrelated symptoms.

According to our results, workers' emotional self-efficacy beliefs in managing negative emotions at work represent a key mechanism linking their basic emotional stability level to burnout symptoms. These results are consistent with previous studies that showed how people high in emotional self-efficacy beliefs are more able to manage the feelings of anxiety aroused by new situations and are less reactive to social distress (Bandura, 1997). As such, emotional self-efficacy is likely to affect workers' ability to deal with difficult organizational situations and enhance perseverance despite possible failures (Bandura, 
1997), events that are especially likely during early phases of organizational socialization. Workers unable to deal with work-related stress will more easily withdraw and succumb in front of adverse work contingencies because of the impact of experienced or anticipated negative emotions on their motivation and self-perception.

Of interest, our study highlighted the importance of adopting a longitudinal design in probing the relationship between personality traits and burnout. Indeed, at the crosssectional level (see Table 1) (1) at T1, burnout is correlated - .79 with emotional stability and -.34 with self-efficacy in managing negative emotions at work, thus $\Delta r=.45$ $(z=-12.693, p<.00001)$; (2) at T2, burnout is correlated -.76 with emotional stability and -.39 with self-efficacy in managing negative emotions at work, thus $\Delta r=.37$ $(z=-10.599, p<.00001)$. Instead, by examining the longitudinal correlations, we found that burnout at T2 is correlated -.49 with emotional stability at T1 and -.37 with self-efficacy in managing negative emotions at work at T1, thus $\Delta r=.12(z=-2.433$, $p=.015)$. This means that the $\Delta$ cross-lagged correlation $(z=-2.433)$ was substantially lower than the $\Delta$ cross-sectional correlations $(z=-12.693$ and $z=-10.599$ at $\mathrm{T} 1$ and $\mathrm{T} 2$, respectively; see Lee \& Preacher, 2013; Steiger, 1980). This finding is important, first because it is likely that cross-sectional correlations are more contaminated by common method bias (Conway \& Lance, 2010), and second because it highlights that, in a crosssectional design, high correlations between emotional stability and burnout may be the result of ignoring (unmeasured) intervening variables.

As demonstrated by our results, possessing robust self-efficacy beliefs in managing negative emotions at work are useful to military cadets for adapting to a new and still not completely known work environment. While adapting to a new and highly structured organizational context, these cadets are naturally faced with unexpected, new, and potentially challenging situations. In these circumstances, it is likely that self-efficacy beliefs in managing negative emotions at work are important in developing one's own sense of competence at work. Perceived competence at work, in turn, may enhance a sense of environmental control and influence one's skills in overcoming the detrimental effects of difficulties, without incurring the development of work-related stress symptoms. That said, we acknowledge that while high self-efficacy in managing negative emotions at work equips workers with higher resistance to stress and lowers the expected impact of dysfunctional personality traits on health-related outcomes, we nonetheless surmise that its benefits do not last forever. Indeed, individuals' self-regulatory abilities may, in the long run, decline as a result of prolonged stress. Thus, in accordance with the COR (Hobfoll, 1989), we cannot exclude the possibility that increased environmental demands may lead, over time, to the need for individuals to invest more resources in the process of emotional self-regulation.

Also, a significant effect of self-efficacy in managing negative emotions at work at T1 on emotional stability at T2 was observed. This is remarkable because the latter is considered to be a trait which, by definition, tends to be relatively stable across time. This effect attests to the malleability of personality traits depicted as individual potentials that need to be actualized (Roberts et al., 2008, p. 384). Indeed, our results strongly supported this perspective, suggesting that workers' personality traits are best conceived not only as 'determinants', but also as 'outcomes' (see Caprara et al., 2013). Indeed, the relationship between emotional stability and emotional self-efficacy beliefs is reciprocal, rather than unidirectional.

Finally, we did not find any evidence for an indirect effect of job burnout on emotional stability through self-efficacy beliefs in managing negative emotions at work. However, although not initially hypothesized, we found a significant prediction of extraversion from job burnout over time. Progressive social withdrawal, loss of enthusiasm, and a gradual 
darkening of mood are common consequences of job burnout (Hakanen \& Schaufeli, 2012; Hillhouse et al., 2000). Thus, it seems likely that one of the long-term effects of job burnout could be represented by lowering individuals' extraversion. At present, this result raises a question regarding the nature of the commonly found negative correlation between extraversion and burnout (Alarcon et al., 2009; Swider \& Zimmerman, 2010). Usually, scholars interpret this correlation as implying that extraverted individuals are less at risk of burnout. However, our results seem to suggest that the opposite interpretation is viable as well. In any case, as this result was exploratory in nature, we acknowledge that our data offer only insights, and not any definitive answers to this interesting question. Accordingly, we recommend researchers try to replicate our results in future studies.

In agreement with previous findings, both emotional stability and self-efficacy in managing negative emotions were characterized by moderately high longitudinal stability (see Caprara et al., 2013; Roberts \& Del Vecchio, 2000). This result confirms the nature of basic traits (such as emotional stability) as stable individual characteristics that are less susceptible to change. Moreover, these findings are in line with our conceptualization of emotional self-efficacy beliefs at work as characteristic adaptations that develop as byproducts of the individuals' interaction with the environment, and which is affected and shaped by the nature of experiences (see Bandura, 1997). Once developed, emotional selfefficacy beliefs may remain very stable across time, as a result of the acquired equilibrium between the individual and its environment (Bandura, 1997).

\section{Practical implications}

From an applied point of view, our research model provides directions for interventions designed to sustain workers' health and to prevent the occurrence of burnout. Whereas one may view emotional stability as a stable personality trait, and thus as a difficult target to address directly in an intervention, self-efficacy beliefs in managing negative emotions represent cognitive structures that are naturally responsive to change. The application of self-efficacy principles to emotional functioning may represent a promising approach to promote effective emotional processing (Kirk, Schutte, \& Hine, 2011). In this regard, social cognitive theory suggests how to promote individuals' positive beliefs on managing negative emotions and dysphoric affect through the techniques of persuasion, imitation, and mastery experiences. Indeed, in the organizational context, these techniques are at the core of coaching and training programmes that aim at the strengthening of workers' self-efficacy.

In practice, empirically validated strategies for the development of self-efficacy in managing negative emotions include training programmes based on reflective learning (Dacre-Pool \& Qualter, 2012) and expressive writing (Kirk et al., 2011). The expressive writing paradigm, for example, requires participants to write about their deepest feelings and thoughts about aspects of life or meaningful events (e.g., King, 2001, 2002). In the study conducted by Kirk et al. (2011), this approach appeared to successfully promote increased levels of emotion self-efficacy, emotional intelligence, and positive affect among workers (see Kirk et al., 2011 for full detail).

\section{Limitations}

The methodological strengths of this study include the use of a complete cohort of military cadets and the two-wave data collection. Moreover, cadets were followed from the beginning when they entered the 'new' situation. While we acknowledge that, in general, 
more time points would have allowed stronger longitudinal analysis and resulting examination of the reciprocal relations among constructs, we note that the natural permanence of military cadets in the academy is fixed to 2 years. In this regard, we suggest that future studies should test the validity of our model in samples of workers from other types of organizations, occupations, and cultures.

The fact that the study involved self-report data may be considered a limitation of our study design. However, one may claim that no one can report on one's own inner characteristics, perceived abilities and feeling of burnout better than participants themselves. Participants, more than other people, may be in the best position to know and account for their own behaviour and health status and, of course, may provide a unique perspective on personality. However, we do not underestimate the possibility that our study could be affected by common method variance, which is 'systematic error variance due to the method of measurement' (Conway \& Lance, 2010, p. 326). Indeed, when all variables that are included in a model stem from the same source of information (e.g., all self-report questionnaires, as in our case), the size of the relationships among constructs may be biased (see Spector, 2006; for a different perspective). Thus, we suggest future research replicate our model using, for example, a mix of self-report and objective data. While to our knowledge, there are no objective or other-report measures of burnout, future studies could replicate our proposed model using exhaustion-related health measures (e.g., Grossi, Perski, Osika, \& Savic, 2015).

Another limitation of our study is that the mediation effect was calculated using a twowave design. In the literature on longitudinal mediation analysis, this kind of design is called a half-longitudinal design. Whereas half-longitudinal designs are indubitable better in probing mediation effects than pure cross-sectional designs (Cole \& Maxwell, 2003; Maxwell \& Cole, 2007; Maxwell, Cole, \& Mitchell, 2011), future studies are needed to confirm our results using full-longitudinal designs (i.e., designs with data gathered at least across three time points).

Finally, we notice that the choice of the time-lag was determined by pragmatic reasons (i.e., the annual cycle of cadets' evaluation as established in the academy) and not based on specific theoretical reasoning. Thus, the adequate time-lag length is worthy of investigation in future studies (see Dormann \& Griffin, 2015).

\section{Conclusion}

We showed that self-efficacy in managing negative emotions at work is an important personal resource for workers, and thus - being a rather new construct in organizational literature - it deserves to be thoroughly investigated in future studies. Furthermore, we discussed how its malleability allows practitioners to design interventions for contrasting stress-related symptoms in the workplace. Yet, throughout the study, we pointed to the importance of taking into account the different layers of personality (i.e., stable traits and social cognitive mechanisms) when studying burnout or similar organizational behaviour constructs. In sum, we hope that the present study has the potential to contribute to the literature by offering important insights for researchers dealing with studies in this field, as well as for practitioners dealing with stress-related symptoms in the workplace.

\section{Funding}

This research was supported in part by a Research Grant (named 'Progetto di Ateneo', No. 1081/2016) awarded by Sapienza University of Rome to Guido Alessandri and by a Starting 
Research Grant (named 'Avvio alla Ricerca', No. 1081/2016, ID: 230929) awarded by Sapienza University of Rome to Enrico Perinelli.

\section{References}

Ahola, K. (2007). Occupational burnout and health. Helsinki, Finland: Finnish Institute of Occupational Health.

Alarcon, G., Eschleman, K. J., \& Bowling, N. A. (2009). Relationships between personality variables and burnout: A meta-analysis. Work \& Stress, 23, 244-263. https://doi.org/10.1080/ 02678370903282600

Alessandri, G., \& Caprara, G. V. (2017). Regulatory emotional self-efficacy beliefs. Technical report: Department of Psychology, Sapienza University of Rome.

Alessandri, G., Vecchione, M., \& Caprara, G. V. (2015). Assessment of regulatory emotional selfefficacy beliefs: A review of the status of the art and some suggestions to move the field forward. Journal of Psychoeducational Assessment, 33, 24-32. https://doi.org/10.1177/ 0734282914550382

Arbuckle, J. L. (1996). Full information estimation in the presence of incomplete data. In G. A. Marcoulides \& R. A. Schumacker (Eds.), Advanced structural equation modeling: Issues and techniques (pp. 243-277). Mahwah, NJ: Lawrence Erlbaum Associates Inc.

Armon, G., Shirom, A., \& Melamed, S. (2012). The big five personality factors as predictors of changes across time in burnout and its facets. Journal of Personality, 80, 403-427. https://doi. org/10.1111/j.1467-6494.2011.00731.x

Bakker, A. B., Demerouti, E., \& Sanz-Vergel, A. I. (2014). Burnout and work engagement: The JD-R approach. Annual Review of Organizational Psychology and Organizational Behavior, 1, 389-411. https://doi.org/10.1146/annurev-orgpsych-031413-091235

Bakker, A. B., \& Heuven, E. (2006). Emotional dissonance, burnout, and in-role performance among nurses and police officers. International Journal of Stress Management, 13, 423-440. https://d oi.org/10.1037/1072-5245.13.4.423

Bakker, A. B., Van Der Zee, K. I., Lewig, K. A., \& Dollard, M. F. (2006). The relationship between the Big Five personality factors and burnout: A study among volunteer counselors. The Journal of Social Psychology, 146, 31-50. https://doi.org/10.3200/SOCP.146.1.31-50

Bandura, A. (1991). Social cognitive theory of self-regulation. Organizational Behavior and Human Decision Processes, 50, 248-287. https://doi.org/10.1016/0749-5978(91)90022-L

Bandura, A. (1997). Self-efficacy: The exercise of self-control. New York, NY: Freeman.

Bandura, A. (1999). A social cognitive theory of personality. In L. A. Pervin \& O. P. John (Eds.), Handbook of personality: Theory and research (2nd ed., pp. 154-196). New York, NY: The Guilford Press.

Bandura, A. (2001). Social cognitive theory: An agentic perspective. Annual Review of Psychology, 52, 1-26. https://doi.org/10.1146/annurev.psych.52.1.1

Bandura, A., Caprara, G. V., Barbaranelli, C., Gerbino, M., \& Pastorelli, C. (2003). Role of affective self-regulatory efficacy in diverse spheres of psychosocial functioning. Child Development, 74 , 769-782. https://doi.org/10.1111/1467-8624.00567

Barbaranelli, C., \& Caprara, G. V. (2000). Measuring the Big Five in self report and other ratings: A multitrait-multimethod study. European Journal of Psychological Assessment, 16, 31-43. https://doi.org/10.1027//1015-5759.16.1.31

Barrick, M. R., \& Mount, M. K. (1991). The big five personality dimensions and job performance: A meta-analysis. Personnel Psychology, 44, 1-26. https://doi.org/10.1111/j.1744-6570.1991. tb00688.x

Bolger, N. (1990). Coping as a personality process: A prospective study. Journal of Personality and Social Psychology, 59, 525-537. https://doi.org/10.1037/0022-3514.59.3.525 
Borgogni, L., Consiglio, C., Alessandri, G., \& Schaufeli, W. B. (2012). "Don't throw the baby out with the bathwater!" Interpersonal strain at work and burnout. European Journal of Work and Organizational Psychology, 21, 875-898. https://doi.org/10.1080/1359432X.2011.598653

Borgogni, L., Galati, D., Petitta, L., \& Centro Formazione Schweitzer. (2005). Il questionario Checkup organizzativo: Manuale dell'adattamento italiano [The organizational Checkup questionnaire: Italian version]. Florence, Italy: Giunti O.S.

Brewer, E. W., \& Shapard, L. (2004). Employee burnout: A meta-analysis of the relationship between age or years of experience. Human Resource Development Review, 3, 102-123. https://doi. org/10.1177/1534484304263335

Burnham, K. P., \& Anderson, D. R. (2004). Multimodel inference understanding AIC and BIC in model selection. Sociological Methods \& Research, 33, 261-304. https://doi.org/10.1177/ 0049124104268644

Caprara, G. V. (2002). Personality psychology: Filling the gap between basic processes and molar functioning. In C. von Hofsten \& L. Bäckman (Eds.), Psychology at the turn of the millennium: Social, developmental, and clinical perspectives (Vol. 2, pp. 201-224). Brighton, UK: Psychology Press.

Caprara, G. V., Alessandri, G., \& Barbaranelli, C. (2010). Optimal functioning: Contribution of selfefficacy beliefs to positive orientation. Psychotherapy and Psychosomatics, 79, 328-330. https://doi.org/10.1159/000319532

Caprara, G. V., Alessandri, G., Di Giunta, L., Panerai, L., \& Eisenberg, N. (2010). The contribution of agreeableness and self-efficacy beliefs to prosociality. European Journal of Personality, 24, 36 55. https://doi.org/10.1002/per.739

Caprara, G. V., Alessandri, A., \& Eisenberg, N. (2012). Prosociality: The contribution of traits, values, and self-efficacy beliefs. Journal of Personality and Social Psychology, 102, 1289-1303. https://doi.org/10.1037/a0025626

Caprara, G. V., Barbaranelli, C., Borgogni, L., \& Vecchione, M. (2007). BFQ-2: Manuale. Florence, Italy: Giunti O.S.

Caprara, G. V., Di Giunta, L., Eisenberg, N., Gerbino, M., Pastorelli, C., \& Tramontano, C. (2008). Assessing regulatory emotional self-efficacy in three countries. Psychological Assessment, 20, 227-237. https://doi.org/10.1037/1040-3590.20.3.227

Caprara, G. V., Vecchione, M., Barbaranelli, C., \& Alessandri, G. (2013). Emotional stability and affective self-regulatory efficacy beliefs: Proofs of integration between trait theory and social cognitive theory. European Journal of Personality, 27, 145-154. https://doi.org/10.1002/per. 1847

Caspi, A., Roberts, B. W., \& Shiner, R. L. (2005). Personality development: Stability and change. Annual Review of Psychology, 56, 453-484. https://doi.org/10.1146/annurev.psych.55. 090902.141913

Chan, D. W. (2006). Emotional intelligence and components of burnout among Chinese secondary school teachers in Hong Kong. Teaching and Teacher Education, 22, 1042-1054. https://doi. org/10.1016/j.tate.2006.04.005

Cheung, G. W., \& Rensvold, R. B. (2002). Evaluating goodness-of-fit indexes for testing measurement invariance. Structural Equation Modeling, 9, 233-255. https://doi.org/10.1207/ S15328007SEM0902_5

Cole, D. A., \& Maxwell, S. E. (2003). Testing mediational models with longitudinal data: Questions and tips in the use of structural equation modeling. Journal of Abnormal Psychology, 112, 558 577. https://doi.org/10.1037/0021-843X.112.4.558

Consiglio, C., Borgogni, L., Alessandri, G., \& Schaufeli, W. B. (2013). Does self-efficacy matter for burnout and sickness absenteeism? The mediating role of demands and resources at the individual and team levels. Work \& Stress, 27, 22-42. https://doi.org/10.1080/02678373.2013. 769325

Conway, J. M., \& Lance, C. E. (2010). What reviewers should expect from authors regarding common method bias in organizational research. Journal of Business and Psychology, 25, 325 334. https://doi.org/10.1007/s10869-010-9181-6 
Costa, P. T., \& McCrae, R. R. (1992). The five-factor model of personality and its relevance to personality disorders. Journal of Personality Disorders, 6, 343-359. https://doi.org/10. 1521/pedi.1992.6.4.343

Costa, P. J., Terracciano, A., \& McCrae, R. R. (2001). Gender differences personality traits across cultures: Robust and surprising findings. Journal of Personality and Social Psychology, 81, 322-331. https://doi.org/10.1037/0022-3514.81.2.322

Dacre-Pool, L., \& Qualter, P. (2012). Improving emotional intelligence and emotional self-efficacy through a teaching intervention for university students. Learning and Individual Differences, 22, 306-312. https://doi.org/10.1016/j.lindif.2012.01.010

Deary, I. J., Watson, R., \& Hogston, R. (2003). A longitudinal cohort study of burnout and attrition in nursing students. Journal of Advanced Nursing, 43, 71-81. https://doi.org/10.1046/j.13652648.2003.02674.x

Demerouti, E., Bakker, A. B., Nachreiner, F., \& Schaufeli, W. B. (2001). The job demands-resources model of burnout. Journal of Applied Psychology, 86, 499-512. https://doi.org/10.1037/ 00219010.86.3.499

Dormann, C., \& Griffin, M. A. (2015). Optimal time lags in panel studies. Psychological Methods, 20, 489-505. https://doi.org/10.1037/met0000041

Eisenberg, N., Cumberland, A., Spinrad, T. L., Fabes, R. A., Shepard, S. A., Reiser, M., . . Guthrie, I. K. (2001). The relations of regulation and emotionality to children's externalizing and internalizing problem behavior. Child Development, 72, 1112-1134. https://doi.org/10.1111/1467-8624. 00337

Ellis, A. M., Bauer, T. N., Mansfield, L. R., Erdogan, B., Truxillo, D. M., \& Simon, L. S. (2015). Navigating uncharted waters: Newcomer socialization through the lens of stress theory. Journal of Management, 41, 203-235. https://doi.org/10.1177/0149206314557525

Enders, C. K. (2010). Applied missing data analysis. New York, NY: The Guilford Press.

Goddard, R., Patton, W., \& Creed, P. (2004). The importance and place of neuroticism in predicting burnout in employment service case managers. Journal of Applied Social Psychology, 34, 282296. https://doi.org/10.1111/j.1559-1816.2004.tb02548.x

Grossi, G., Perski, A., Osika, W., \& Savic, I. (2015). Stress-related exhaustion disorder-clinical manifestation of burnout? A review of assessment methods, sleep impairments, cognitive disturbances, and neuro-biological and physiological changes in clinical burnout. Scandinavian Journal of Psychology, 56, 626-636. https://doi.org/10.1111/sjop.12251

Hakanen, J. J., \& Bakker, A. B. (2017). Born and bred to burn out: A life-course view and reflections on job burnout. Journal of Occupational Health Psychology, 22, 354-364. https://doi.org/10. 1037/ocp0000053

Hakanen, J. J., \& Schaufeli, W. B. (2012). Do burnout and work engagement predict depressive symptoms and life satisfaction? A three-wave seven-year prospective study. Journal of Affective Disorders, 141, 415-424. https://doi.org/10.1016/j.jad.2012.02.043

Hayes, A. F., \& Scharkow, M. (2013). The relative trustworthiness of inferential tests of the indirect effect in statistical mediation analysis: Does method really matter? Psychological Science, 24, 1918-1927. https://doi.org/10.1177/0956797613480187

Heppner, P. P., Cook, S. W., Wright, D. M., \& Johnson, W. C. (1995). Progress in resolving problems: A problem-focused style of coping. Journal of Counseling Psychology, 42, 279-293. https://doi. org/10.1037/0022-0167.42.3.279

Hillhouse, J. J., Adler, C. M., \& Walters, D. N. (2000). A simple model of stress, burnout and symptomalogy in medical residents: A longitudinal study. Psychology, Health \& Medicine, 5, 63 73. https://doi.org/10.1080/135485000106016

Hobfoll, S. E. (1989). Conservation of resources: A new attempt at conceptualizing stress. American Psychologist, 44, 513-524. https://doi.org/10.1037/0003-066X.44.3.513

Hobfoll, S. E. (2001). The influence of culture, community, and the nested-self in the stress process: Advancing conservation of resources theory. Applied Psychology: An International Review, 50, 337-421. https://doi.org/10.1111/1464-0597.00062 
Hobfoll, S. E., \& Shirom, A. (2001). Conservation of resources theory: Applications to stress and management in the workplace. In R. T. Golembiewski (Ed.), Handbook of organizational behavior (pp. 57-80). New York, NY: Marcel Dekker.

Hurtz, G. M., \& Donovan, J. J. (2000). Personality and job performance: The Big Five revisited. Journal of Applied Psychology, 85, 869-879. https://doi.org/10.1037//0021-9010.85. 6.869

Jackson, J. J., Hill, P. L., \& Roberts, B. W. (2012). Misconceptions of traits continue to persist: A response to Bandura. Journal of Management, 38, 745-752. https://doi.org/10.1177/ 0149206312438775

Joardar, A., \& Matthews, L. M. (2010). An empirical investigation of group acceptance using the Big Five personality domains. Organization Management Journal, 7, 194-207. https://doi.org/10. 1057/omj.2010.26

John, O. P., Naumann, L. P., \& Soto, C. J. (2008). Paradigm shift to the integrative Big Five trait taxonomy: History, measurement, and conceptual issues. In O. P. John, R. W. Robins, \& L. A. Pervin (Eds.), Handbook of personality: Theory and research (3rd ed., pp. 114-158). New York, NY: The Guilford Press.

Jones, M. C., Smith, K., \& Johnston, D. W. (2005). Exploring the Michigan model: The relationship of personality, managerial support and organizational structure with health outcomes in entrants to the healthcare environment. Work \& Stress, 19, 1-22. https://doi.org/10.1080/ 02678370500065325

Judge, T. A., Heller, D., \& Mount, M. K. (2002). Five-factor model of personality and job satisfaction: A meta-analysis. Journal of Applied Psychology, 87, 530-541. https://doi.org/10.1037/00219010. 87.3 .530

Judge, T. A., Jackson, C. L., Shaw, J. C., Scott, B. A., \& Rich, B. L. (2007). Self-efficacy and work-related performance: The integral role of individual differences. Journal of Applied Psychology, 92, 107-127. https://doi.org/10.1037/0021-9010.92.1.107

Kim, H. J., Shin, K. H., \& Swanger, N. (2009). Burnout and engagement: A comparative analysis using the Big Five personality dimensions. International Journal of Hospitality Management, 28, 96-104. https://doi.org/10.1016/j.ijhm.2008.06.001

Kim, H. J., Shin, K. H., \& Umbreit, W. T. (2007). Hotel job burnout: The role of personality characteristics. International Journal of Hospitality Management, 26, 421-434. https://doi. org/10.1016/j.ijhm.2006.03.006

King, L. A. (2001). The health benefits of writing about life goals. Personality and Social Psychology Bulletin, 27, 798-807. https://doi.org/10.1177/0146167201277003

King, L. A. (2002). Gain without pain? Expressive writing and self-regulation. In S. J. Lepore \& J. A. Smyth (Eds.), The writing cure: How expressive writing promotes health and emotional wellbeing (pp. 119-134). Washington, DC: American Psychological Association. https://doi.org/10. 1037/10451-006

Kirk, B. A., Schutte, N. S., \& Hine, D. W. (2011). The effect of an expressive writing intervention for employees on emotional self-efficacy, emotional intelligence, affect, and workplace incivility. Journal of Applied Social Psychology, 41, 179-195. https://doi.org/10.1111/j.1559-1816.2010. 00708.x

Kline, R. B. (2016). Principles and practice of Structural Equation Modeling (4th ed.). New York, NY: The Guilford Press.

Lee, I. A., \& Preacher, K. J. (2013, September). Calculation for the test of the difference between two dependent correlations with one variable in common [Computer software]. Retrieved from http://quantpsy.org

Little, T. D., Cunningham, W. A., Shahar, G., \& Widaman, K. F. (2002). To parcel or not to parcel: Exploring the question, weighing the merits. Structural Equation Modeling, 9, 151-173. https://doi.org/10.1207/S15328007SEM0902_1

Little, T. D., Rhemtulla, M., Gibson, K., \& Schoemann, A. M. (2013). Why the items versus parcels controversy needn't be one. Psychological Methods, 18, 285-300. https://doi.org/10.1037/ a0033266 
MacKinnon, D. P. (2008). Introduction to statistical mediation analysis. New York, NY: Lawrence Erlbaum Associates.

MacKinnon, D. P., Lockwood, C. M., Hoffman, J. M., West, S. G., \& Sheets, V. (2002). A comparison of methods to test mediation and other intervening variable effects. Psychological Methods, 7, 83104. https://doi.org/10.1037/1082-989X.7.1.83

Maslach, C., Jackson, S. E., \& Leiter, M. P. (1996). Maslach Burnout Inventory manual (3rd ed.). Palo Alto, CA: Consulting Psychologist Press.

Maslach, C., Schaufeli, W. B., \& Leiter, M. P. (2001). Job burnout. Annual Review of Psychology, 52, 397-422. https://doi.org/10.1146/annurev.psych.52.1.397

Maxwell, S. E., \& Cole, D. A. (2007). Bias in cross-sectional analyses of longitudinal mediation. Psychological Methods, 12, 23-44. https://doi.org/10.1037/1082-989X.12.1.23

Maxwell, S. E., Cole, D. A., \& Mitchell, M. A. (2011). Bias in cross-sectional analyses of longitudinal mediation: Partial and complete mediation under an autoregressive model. Multivariate Behavioral Research, 46, 816-841. https://doi.org/10.1080/00273171.2011.606716

McAdams, D. P. (1995). What do we know when we know a person? Journal of Personality, 63, 365-396. https://doi.org/10.1111/j.1467-6494.1995.tb00500.x

McCrae, R. R., \& Costa, P. T. (1990). Personality in adulthood. New York, NY: The Guilford Press.

McCrae, R. R., \& Costa, P. T. (2008). The Five-Factor theory of personality. In O. P. John, R. W. Robins, \& L. A. Pervin (Eds.), Handbook of personality: Theory and research (3rd ed., pp. 159181). New York, NY: Guilford.

Mikolajczak, M., Menil, C., \& Luminet, O. (2007). Explaining the protective effect of trait emotional intelligence regarding occupational stress: Exploration of emotional labour processes. Journal of Research in Personality, 41, 1107-1117. https://doi.org/10.1016/j.jrp.2007.01.003

Milioni, M., Alessandri, G., Eisenberg, N., Castellani, V., Zuffianò, A., Vecchione, M., \& Caprara, G. V. (2015). Reciprocal relations between emotional self-efficacy beliefs and ego-resiliency across time. Journal of Personality, 83, 552-563. https://doi.org/10.1111/jopy.12131

Muthén, L. K., \& Muthén, B. O. (1998-2015). Mplus user's guide (7th ed.). Los Angeles, CA: Author.

Petrides, K. V. (2011). Ability and trait emotional intelligence. In T. Chamorro-Premuzic, S. von Stumm, \& A. Furnham (Eds.), The Wiley-Blackwell handbook of individual differences (pp. 656-678). Hoboken, NJ: John Wiley \& Sons Inc.

Piedmont, R. L. (1993). A longitudinal analysis of burnout in the health care setting: The role of personal dispositions. Journal of Personality Assessment, 61, 457-473. https://doi.org/10. 1207/s15327752jpa6103_3

Purvanova, R. K., \& Muros, J. P. (2010). Gender differences in burnout: A meta-analysis. Journal of Vocational Behavior, 77, 168-185. https://doi.org/10.1016/j.jvb.2010.04.006

Roberts, B. W., \& Del Vecchio, W. F. (2000). The rank-order consistency of personality traits from childhood to old age: A quantitative review of longitudinal studies. Psychological Bulletin, 126, 3-25. https://doi.org/10.1037/0033-2909.126.1.3

Roberts, B. W., Wood, D., \& Caspi, A. (2008). The development of personality traits in adulthood. In O. P. John, R. W. Robins, \& L. A. Pervin (Eds.), Handbook of personality: Theory and research (3rd ed., pp. 375-398). New York, NY: Guilford Press.

Saks, A. M. (1994). Moderating effects of self-efficacy for the relationship between training method and anxiety and stress reactions of newcomers. Journal of Organizational Behavior, 15, 639654. https://doi.org/10.1002/job. 4030150707

Salgado, J. F. (2002). The Big Five personality dimensions and counterproductive behaviors. International Journal of Selection and Assessment, 10(1-2), 117-125. https://doi.org/10. $1111 / 1468-2389.00198$

Schaufeli, W. B., Bakker, A. B., \& Van Rhenen, W. (2009). How changes in job demands and resources predict burnout, work engagement, and sickness absenteeism. Journal of Organizational Behavior, 30, 893-917. https://doi.org/10.1002/job.595

Schaufeli, W. B., \& Enzmann, D. (1998). The burnout companion to study and research: A critical analysis. London, UK: Taylor \& Francis. 
Seibert, S. E., \& Kraimer, M. L. (2001). The five-factor model of personality and career success. Journal of Vocational Behavior, 58, 1-21. https://doi.org/10.1006/jvbe.2000.1757

Shoji, K., Cieslak, R., Smoktunowicz, E., Rogala, A., Benight, C. C., \& Luszczynska, A. (2016). Associations between job burnout and self-efficacy: A meta-analysis. Anxiety Stress and Coping, 29, 367-386. https://doi.org/10.1080/10615806.2015.1058369

Specht, J., Egloff, B., \& Schmukle, S. (2011). Stability and change of personality across the life course: The impact of age and major life events on mean-level and rank-order stability of the Big Five. Journal of Personality and Social Psychology, 101, 862-882. https://doi.org/10.1037/ a0024950

Spector, P. (2006). Method variance in organizational research: Truth or urban legend? Organizational Research Methods, 9, 221-232. https://doi.org/10.1177/1094428105284955

Spector, P. E., \& O'Connell, B. J. (1994). The contribution of personality traits, negative affectivity, locus of control and Type A to the subsequent reports of job stressors and job strains. Journal of Occupational and Organizational Psychology, 67, 1-12. https://doi.org/10.1111/j.20448325.1994.tb00545.x

Steiger, J. H. (1980). Tests for comparing elements of a correlation matrix. Psychological Bulletin, 87, 245-251. https://doi.org/10.1037/0033-2909.87.2.245

Swider, B. W., \& Zimmerman, R. D. (2010). Born to burnout: A meta-analytic path model of personality, job burnout, and work outcomes. Journal of Vocational Behavior, 76, 487-506. https://doi.org/10.1016/j.jvb.2010.01.003

Ullrich, A., Lambert, R. G., \& McCarthy, C. J. (2012). Relationship of German elementary teachers' occupational experience, stress, and coping resources to burnout symptoms. International Journal of Stress Management, 19, 333-342. https://doi.org/10.1037/a0030121

Wright, T. A., \& Bonett, D. G. (1997). The contribution of burnout to work performance. Journal of Organizational Behavior, 18, 491-499. https://doi.org/10.1002/(SICI)1099-1379(199709)18: 5<491:AID-JOB804>3.0.CO;2-I

Zysberg, L., Orenshtein, C., Gimmon, E., \& Robinson, R. (2017). Emotional Intelligence, personality, stress, and burnout among educators. International Journal of Stress Management, 24(Suppl 1), 122-136. https://doi.org/10.1037/str0000028

Received 25 August 2017; revised version received 21 May 2018

\section{Appendix I: The six items used for assessing Self-Efficacy Beliefs in Managing Negative Emotions at Work drawn and adapted for organizational contexts from the Regulatory Emotional Self-Efficacy Scale introduced and validated by Caprara et al. (2008).}

Introductory question: "At work, how well can you:"

1). Reduce your upset when your superior don't get you the appreciation you feel you deserve?

2). Maintain your self-control in every circumstance?

3). Get over irritation quickly after the experience of a failure?

4). Keep calm during stressful and straining situations?

5). Avoid getting upset when others keep giving you a hard time?

6). Get over irritation quickly for wrongs you have experienced?

Respondents indicated agreement with the extent to which each item described them on a 5-point scale ranging from 1 (not well at all) to 5 (very well). 


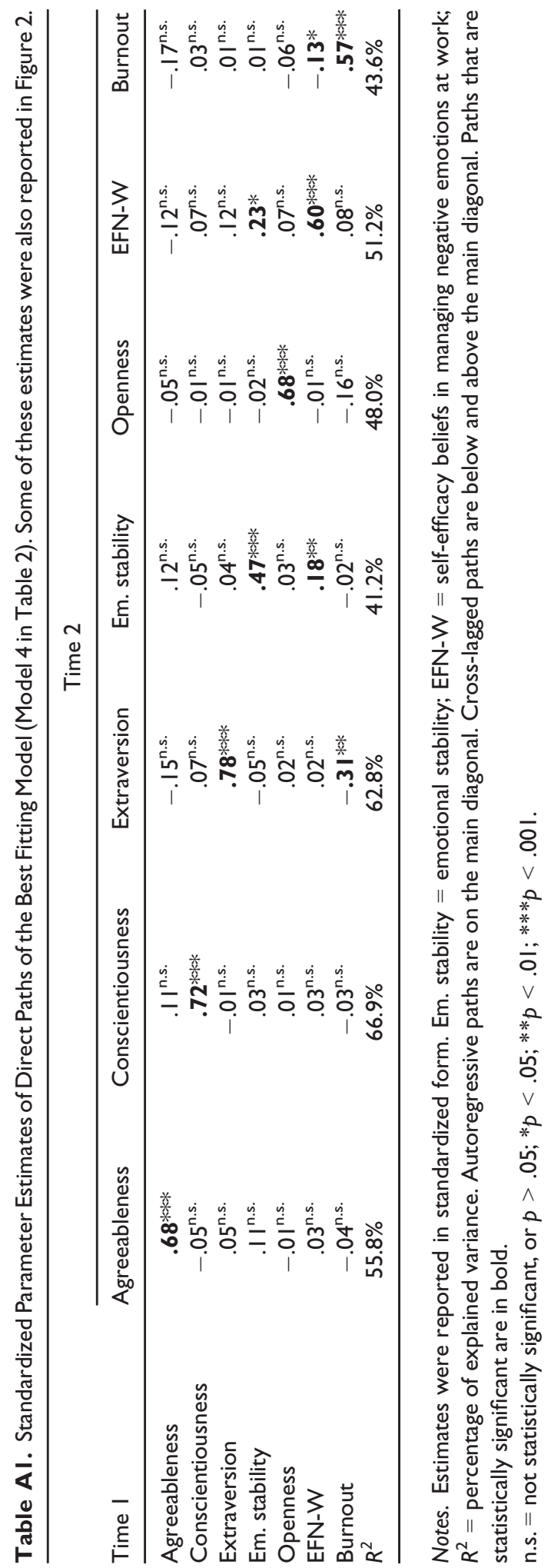


Table A2. Standardized Covariances Among Latent Variables of the Best Fitting Model (Model 4 in Table 2). Some of these estimates were also reported in Figure 2.

\begin{tabular}{lccccccc}
\hline & $(1)$ & $(2)$ & $(3)$ & $(4)$ & $(5)$ & $(6)$ & $(7)$ \\
\hline 1) Agreeableness & - & $.55^{* * *}$ & $.52^{* * *}$ & $.39^{* * *}$ & $.27^{* * *}$ & $.31^{* * *}$ & $-.33^{* * *}$ \\
2) Conscientiousness & $.75^{* * *}$ & - & $.50^{* * *}$ & $.15^{\text {n.s. }}$ & $.48^{* * *}$ & $.16^{\text {n.s. }}$ & $-.17^{*}$ \\
3) Extraversion & $.57^{* * *}$ & $.5 I^{* * *}$ & - & $.23^{* *}$ & $.38^{* * *}$ & $.01^{\text {n.s. }}$ & $-.18^{*}$ \\
4) Em. stability & $.28^{* * *}$ & $.12^{\text {n.s. }}$ & $.07^{\text {n.s. }}$ & - & $.10^{\text {n.s. }}$ & $.37^{* * *}$ & $-.70^{* * *}$ \\
5) Openness & $.48^{* * *}$ & $.45^{* * *}$ & $.43^{* * *}$ & $-.01^{\text {n.s. }}$ & - & $.02^{\text {n.s. }}$ & $-.06^{\text {n.s. }}$ \\
6) EFN-W & $.45^{* * *}$ & $.29^{* * *}$ & $.25^{* * *}$ & $.46^{* * *}$ & $.15^{* *}$ & - & $-.20^{* *}$ \\
7) Burnout & $-.29^{* * *}$ & $-.08^{\text {n.s. }}$ & $-.03^{\text {n.s. }}$ & $-.80^{* * *}$ & $-.02^{\text {n.s. }}$ & $-.37^{* * *}$ & - \\
\hline
\end{tabular}

Notes. Estimates were reported in standardized form. Em. stability = emotional stability; EFN-W = selfefficacy beliefs in managing negative emotions at work.

Values below the diagonal refer to Time I; values above the diagonal refer to Time 2 .

n.s. = not statistically significant, or $p>.05 ; * p<.05 ; * * p<.01 ; * * p<.001$. 